\title{
CARACTERIZAÇÃO DA DINÂMICA DEMOGRÁFICA DA AMAZÔNIA LEGAL E PROJEÇÃO POPULACIONAL MUNICIPAL
}

\author{
Aline Silva de Oliveira* \\ Ricardo Alexandrino Garcia \\ Alfredo Costa
}

\section{Resumo}

A partir dos censos demográficos do IBGE (1970, 1980, 1991, 2000) realizou-se nesse trabalho uma análise da dinâmica demográfica recente da Amazônia Legal a partir da caracterização de suas principais componentes, mortalidade, fecundidade e migração. Um dos principais resultados dessa análise foi à constatação de um alto crescimento populacional que provocou uma urbanização intensa e acelerada na região. Nesse contexto apresenta-se uma breve análise sobre os acontecimentos que culminaram a urbanização da Amazônia Legal durante sua história. A urbanização da região possui um caráter relativo e constitui foco de estudo de alguns trabalhos importantes como (BECKER, 2005; AMARAL et al, 2001 e HOGAN et al, 2008). Entretanto o objetivo principal desse trabalho consiste em uma avaliação dos resultados da projeção populacional dos 808 municípios amazônicos. Para tal foram utilizadas as estimativas populacionais do IBGE (2008) e uma metodologia de projeção de pequenas áreas, elaborada a partir do "Método dos Coeficientes", também conhecido por AiBi (CARVALHO \& GARCIA 2004; JANNUZI, 2006). A partir das populações projetadas pela nova revisão do IBGE de 2008, elaborou-se uma metodologia para a projeção de áreas menores, tendo como base a projeção do Brasil. Uma vez obtidas estimativas confiáveis da evolução populacional brasileira, entre 2000 a 2050 (IBGE, 2008) foi possível projetar os contingentes populacionais dos municípios que integram a Amazônia Legal, por sexo e situação de domicilio para os anos de 2005 a 2050.

Palavras-chave:Dinâmica Demográfica; Amazônia Legal; Projeção Populacional

\footnotetext{
*Mestranda em Modelagem de Sistemas Ambientais/UFMG.

- Prof. Adjunto do Departamento Geografia Instituto de Geociências/UFMG.

`Mestrando em Cartografia pela Universidade Federal de Minas Gerais /UFMG. 


\section{1- INTRODUÇÃO}

A Amazônia Legal desde 1970 lida com o crescimento da urbanização mensurada pela alteração no tamanho das cidades já existentes e pelo surgimento de novas sedes municipais. As cidades da Amazônia são palcos de uma dinâmica urbana intensa devido à constante formação de novos núcleos populacionais. Tal fator caracteriza um processo de urbanização ainda em fase de estruturação, já que a região também permanece como fronteiriça ${ }^{1}$. Nesse contexto novas políticas direcionadas, principalmente ao planejamento urbano, surgem ao longo dos anos com objetivo de promover o desenvolvimento regional. Por essas características, informações geradas por projeções populacionais apresentam-se como valiosas ferramentas para a orientação das atividades de planejamento e das políticas de gestão urbana dessa região e de seus novos municípios (AMARAL et al, 2001).

Cabe mencionar que existe um grande foco de discussão em relação à Amazônia nocenário nacional e internacional no que se refere à exploração de capital natural e devastação do seu ecossistema. Dessa forma a aquisição de novas informações, principalmente, o levantamento de dados que colaboram para estudos prospectivos, sempre terá uma importância ímpar quando a área em análise se trata da Amazônia e de seus serviços ecológicos.

A aplicação do método AiBi para a projeção de pequeníssimas áreas, ou seja, na geração de dados mais desagregados foi realizada nesse trabalho para fornecer denominadores estimados de forma mais consistentes, ou seja com um detalhamento geográfico maior - o que torna esses dados uma garantia para a tomada de medidas realmente úteis na construção de um planejamento urbano comprometido com a realidade empírica da Amazônia Legal. A partir da aplicação da técnica de projeção populacional $\mathrm{AiBi}$, esse trabalho tem por objetivo principal a elaboração de estimativas populacionais, segundo sexo e situação de domicilio dos municípios que compõem a Amazônia Legal no período de 2005 a 2050. Realizadas essas estimativas, elaborou-se um mapeamento para analisar a dinâmica da distribuição espaço-temporal do contingente populacional da região, entre os anos projetados.

A caracterização e a análise da dinâmica demográfica recente da Amazônia Legal também foram realizadas para se entender as tendências atuais do comportamento populacional - levando em conta suas principais variáveis (fecundidade, mortalidade e migração) - com o objetivo de fornecer mais uma fonte de coleta de informações colaborativas no tocante a delineação de perspectivas futuras para essa região. A AmazôniaLegal sofre de uma dinâmica populacional determinada nos últimos anos por

\footnotetext{
“"zona de interpenetração mútua e de constante manipulação de estruturas sociopolíticas, econômica eculturais” (BECKER, 2006, pg. 45.) 
diversos fatores demográficos, econômicos e sociais - influenciada por ações governamentais internas e por outras regiões - o que enfatizaria a necessidade de se dispor de cenários futuros multidisciplinares ${ }^{2}$.

\section{2- METODOLOGIA ${ }^{3}$}

Projetar uma população analisando a contribuição de uma área pequena no crescimento absoluto da população esperada na área maior consiste na utilização de umaprojeção populacional que vise à participação no crescimento. Esse tipo de projeção tem origem desde 1959, com Pickard, que a denomina como “Apportionment Method”(CARVALHO \& GARCIA, 2004). ). Em 1972 esse método passou a ser utilizado no Brasil,primeiro por MADEIRA \& SIMÕES, e posteriormente por diversos autores como CARVALHO \& GARCIA (2004) e JANNUZI (2006), sendo conhecido como AiBi.

A metodologia adotada nesse trabalho compreende, portanto, uma projeção de pequenas áreas, baseada na aplicação do Método de Participação no Crescimento (AiBi). Apartir das propostas de CARVALHO E GARCIA (2004) e IBGE (2008), pretende-se em umaprimeira etapa projetar a população total dos municípios da Amazônia Legal, segundo sexo esituação de domicílio. Posteriormente será aplicada a Técnica dos Pesos Relativos "que consiste na projeção dos contingentes distritais, por sexo e situação de domicílio, realizada com base na manutenção dos percentuais observados no último período conhecido do período imediatamente anterior" (CARVALHO E GARCIA, 2004, pg. 9).

Como o método AiBi necessita de uma projeção populacional para uma área maior(Estado ou o País), uma vez que área menor que se pretende projetar, nesse caso o município,pertence a essa maior área, utilizou-se a projeção do IBGE para o Brasil (IBGE, 2008) .Uma vez obtidas estimativas confiáveis da evolução populacional brasileira, entre 1980 a 2050,foram projetados os contingentes populacionais dos municípios que integram a Amazônia Legal, por sexo e situação de domicilio para os anos de 2000 a 2050.

Segundo JANNUZI (2006) o emprego da técnica AiBi se faz apropriada, por exemplo, em cenários que se dispõe apenas de totais populacionais para as pequeníssimas áreas, onde se imagina que a dinâmica populacional futura esteja fortemente condicionada pela evolução tendencial passada. No Brasil, tanto as estimativas oficiais de populações de subdivisões geográficas como as estimativas de todos os municípios do País, são feitas pelo IBGE a partir desse método.

Segundo CARVALHO \& GARCIA (2004) a expressão analítica desse modelo é dada

por:

\footnotetext{
2 "Cenários Futuros são abstrações contextuais multidisciplinares acerca de possíveis trajetórias futuras da realidade social e econômica de uma sociedade" (JANNUZI, 2006, pg. 17).

${ }^{3}$ Essa metodologia foi baseada na utilizada por Ricardo Alexandrino Garcia (professor adjunto do IGC-UFMG)em seu relatório técnico-científico para o projeto: Diagnóstico Sócio Ambiental da Bacia do Mucuri em Minas Gerais; Geohistória, (Re) Estruturações Espaciais, Desenvolvimento Humano e Econômico. Instituto de Geociências Aplicadas. 2008.
} 


\section{Equação 1}

$$
P m_{t i}=a_{i}+b_{i} \operatorname{Pr}_{t}
$$

na qual: Pmti é a população da área menor i no tempo t; ai é o coeficiente linear de correção da população da área menor i em relação a sua área maior; bi, o coeficiente de proporcionalidade do crescimento da população da área menor em relação ao crescimento dapopulação da área maior; Prt, população da UF no ano t.

Como o somatório de Pmti é igual a Prt, isso quer dizer que o somatório de ai é iguala 0 e o somatório de bi igual a 1, não havendo, portanto, necessidade de compatibilização final das estimativas, pois a consistência interna entre os estados e seus municípios está garantida. Segundo CARVALHO \& GARCIA (2004):

“A operacionalização do modelo se dá mediante a participação relativa de cada área menor no crescimento da área maior, calculada com base na diferença relativa entre a população da área menor e a da área maior em dois momentos no passado. A multiplicação desta proporção pelo crescimento absoluto da área maior do período que se deseja projetar resulta no crescimento esperado para cada área menor"'(pg.20).

Esse crescimento, somado à população da área menor, no início do período, dá origem à população projetada no final do período. A equação utilizada para projetar a população de uma área menor no ano $t$, num período $\mathrm{x}$, é a seguinte:

\section{Equação 1}

$$
P m_{t}=P m_{t-x}+\frac{P m_{t-x}-P m_{t-2 x}}{\operatorname{Pr}_{t-x}-\mathrm{Pr}_{t-2 x}}\left(\mathrm{Pr}_{t}-\mathrm{Pr}_{t-x}\right) \text {, }
$$

na qual: Pmt é a população da área menor no ano t; Pmt-x a população da área menor no anot-x; Pmt-2x é a população da área menor no ano t-2x; população da área maior no ano t; Prt-x, a população da área maior no ano t-x; Prt-2x, a população da área maior no ano t-2x; Prt.

CARVALHO \& GARCIA (2004) nos salienta ainda que quando o crescimento dapopulação da área maior e o de uma área menor caminham em direções opostas há a possibilidade de esse método gerar uma inconsistência nos resultados, que reflete no aparecimento de populações negativas. Outro problema dessa metodologia é levantado por SZWARCWALD (1989). A autora afirma que no método AiBi o modelo de crescimento da subpopulação fica determinado pelo da população total, ou seja, a 
interpolação linear é usada para a população total e as subpopulações são conseqüentemente projetadas linearmente, oque nem sempre é uma suposição apropriada.

No entanto é importante reconhecer que o método AiBi carrega consigo a vantagem de independência na seqüência de desagregações sucessivas. Além disso, como afirma

JANNUZI (2006):

"Se por um lado, esse método correlato de repartição populacional apresenta forte viés extrapolativo inercial do passado recente do município, por outro, parece ser um método adequado para a carência de registros e estatísticas periódicas, confiáveis e comparáveis em nível municipal no Brasil” (pg. 20).

A partir do método AiBi foi possível, portanto, projetar os municípios que compõem a Amazônia Legal, fornecendo dados de alto detalhamento geográfico como subsídios para quepesquisadores possam elaborar cenários demográficos futuros.

\section{3- CARACTERIZAÇÂO DA DINÂMICA DEMOGRÁFICA RECENTE DA AMAZÔNIA LEGAL}

A Amazônia Legal foi instituída através de dispositivo de lei para fins de planejamento econômico e ambiental da região amazônica. A definição legal da Amazônia Legal, contudo, surgiu na década de 1950, no contexto da criação e regulamentação da Superintendência do Plano de Valorização da Amazônia - SPVEA, (BECKER, 2006). Engloba os Estados da macrorregião Norte (Acre, Amazonas, Amapá, Pará, Rondônia, Roraima e Tocantins), mais o Estado do Mato Grosso (macrorregião Centro-Oeste), parte do Maranhão, a oeste do meridiano de $44^{\circ}$ (macrorregião Nordeste) e cinco municípios de Goiás cortados pelo paralelo $13^{\circ}$, totalizando 808 municípios (IBGE, 2005). 


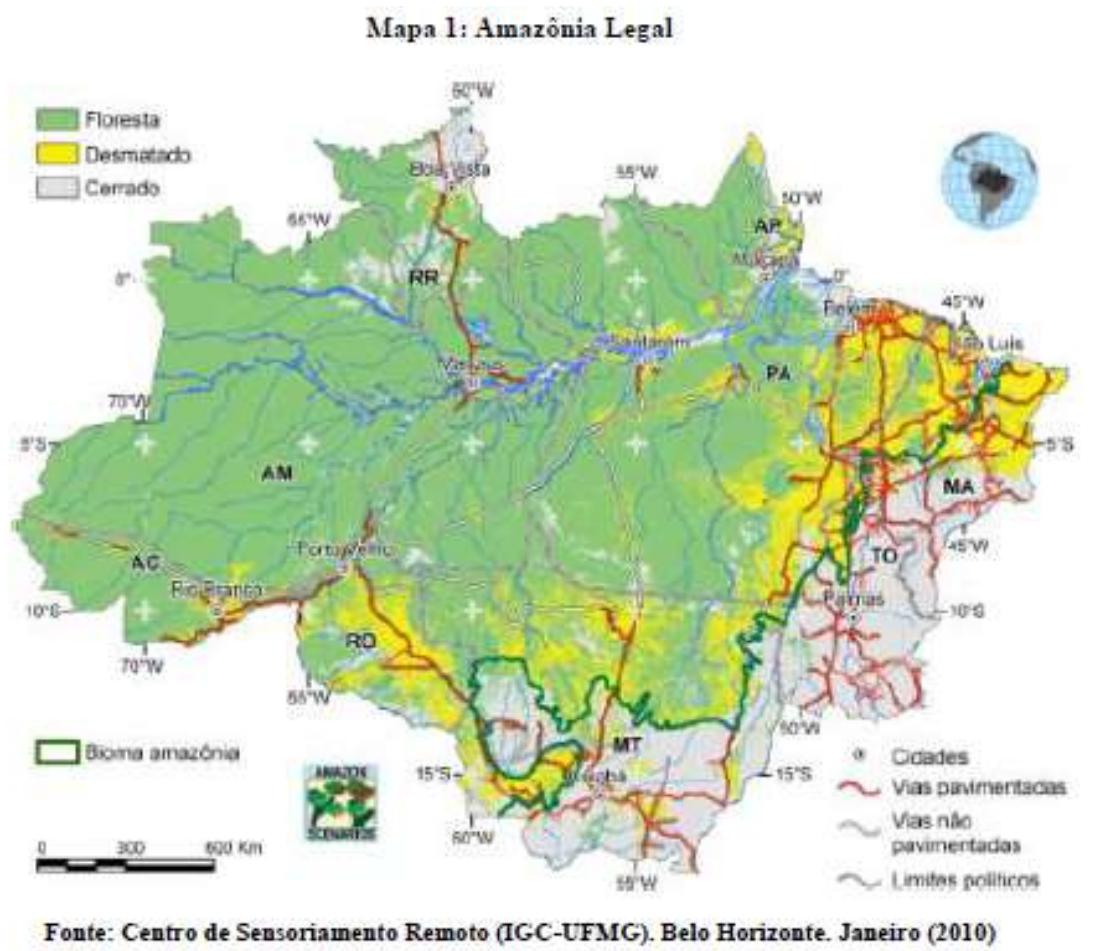

A caracterização da dinâmica demográfica recente da Amazônia Legal foi realizada a partir dos censos demográficos do Instituto Brasileiro de Geografia e Estatística - IBGE (1970,1980,1991,2000). Junto a essa caracterização foram relatados os principais acontecimentos históricos e processos econômicos que delinearam o comportamento populacional da região. Para as análises da mortalidade e da fecundidade também foram incluídos os dados de 2004 e 2007. É importante salientar que para os estados do Maranhão, Mato Grosso e Goiás foram selecionados somente os dados dos municípios que pertencem a Amazônia Legal.

\subsection{Análise do ritmo de crescimento Populacional e Grau de Urbanização}

Com taxas de crescimento anual acima da média do país a população da Amazônia legal cresceu continuamente durante os anos de 1970 a 2000. Em correspondência ao desenvolvimento regional promovido pela política de integração do governo, o crescimento alto e acelerado teve maior destaque entre os anos de 1970 e 1980, atingindo uma taxa de 4,44\%. Todos os estados componentes da região acompanharam a mesma tendência, sendo que Rondônia e Roraima foram os que mais cresceram. Enquanto em Rondônia a população aumentou doze vezes, em Roraima a população em 2000 era oito vezes maior que em 1970.

As populações das demais unidades de federação da região norte alcançaram mais que o dobro do número de habitantes durante essas três décadas, com exceção de Maranhão - apesar desse estado também ter apresentado crescimento exorbitante. 
Tabela 1

\begin{tabular}{|c|c|c|c|}
\hline \multirow{2}{*}{$\begin{array}{l}\text { Unidades } \\
\text { De } \\
\text { Federação }\end{array}$} & \multicolumn{3}{|c|}{ Taxa de Crescimento Anual (\%) } \\
\hline & $\begin{array}{c}1970- \\
1980\end{array}$ & $\begin{array}{l}1980- \\
1991\end{array}$ & $\begin{array}{c}1991- \\
2000\end{array}$ \\
\hline BRASIL & 2,48 & 1,93 & 1,64 \\
\hline Rondônia & 16,03 & 7,89 & 2,24 \\
\hline Acre & 3,42 & 3,01 & 3,29 \\
\hline Amazonas & 4,12 & 3,57 & 3,31 \\
\hline Roraima & 6,83 & 9,63 & 4,58 \\
\hline Pará & 4,62 & 3,46 & 2,54 \\
\hline Amapá & 4,36 & 4,67 & 5,77 \\
\hline Tocantins & 3,56 & 2,01 & 2,61 \\
\hline NORTE & 5,02 & 3,85 & 2,86 \\
\hline Maranhão & 3,09 & 2,1 & 1,63 \\
\hline M. Grosso & 2,99 & 1,45 & 0,98 \\
\hline Goiás & 6,64 & 5,38 & 2,4 \\
\hline AM.LEGAL & 4,44 & 3,53 & 2,48 \\
\hline
\end{tabular}

Os elevados níveis de fecundidade e os baixos níveis de mortalidade que prevalecemna população da Amazônia Legal (ainda maiores que a media nacional), e também a migração, são os fatores condicionantes desse elevado crescimento. Esses fluxos migratórios significativos motivados pela abertura de estradas e pelos projetos de ocupação foram destinados principalmente ao estado de Rondônia que respondia em 1970 por aproximadamente 70\% da produção nacional de minério.

Apesar do alto crescimento populacional da região e das unidades federativas, as taxas demonstram declínio ao passar dos anos. O Amapá foi o único estado que demonstrou aumento da taxa de crescimento populacional anual durante todo período de 1970 a 2000.Apesar de sua população estar entre as menores de toda região, as taxas de crescimento verificadas no estado foram muito expressivas desde 1970. No período de 1980 a 1991, por exemplo, a taxa de crescimento do Amapá foi cerca de 32\% maior que a da Amazônia Legal e 21 \% maior que a da região norte. De 1991 a 2000 essa taxa era cerca de duas vezes maior que a média de ambas as regiões. Além do incentivo ao desenvolvimento regional, o crescimento alto da população do Amapá é conseqüente da mineração de manganês na Serra do Návio que se desenvolveu desde 1945, e da criação do estado em 1988.

A localização de 70\% do total dos habitantes em apenas três estados (Pará, 29,5\%), Maranhão $(29 \%)$ e Amazonas (13\%), delineia um perfil concentrador da distribuição populacional entre os estados da Amazônia Legal. Ressalta-se, no entanto, que a população do estado do Maranhão vem diminuindo a sua participação relativa, passando de 41\% em 1970 para 27\% em 2000.

O crescimento populacional da Amazônia Legal corresponde principalmente ao incremento da população urbana. A evolução da taxa de crescimento populacional urbana da região se deu de modo similar a da população total do país, ou seja, diminuiu ao passar dos

anos, porém se manteve alta - apesar das taxas nacionais se apresentarem bem menores que as taxas da região. 
O processo de urbanização se intensificou desde 1970, época em que a população urbana já correspondia a $37 \%$ da população total. O alto crescimento de $6,64 \%$, fez com que essa população aumentasse para 44,6\% em 1980. Em 1991 já correspondia a 58\% e em 2000 a 69\% do total de habitantes da Amazônia Legal. No entanto, a proporção da população urbana regional não é igual à das demais regiões do país, um dos fatores seria a forte permanência da população rural no estado do Maranhão que reduz essa proporção para o conjunto da região (BECKER, 2005).

Segundo BECKER (1998) as grandes diversificações das atividades econômicas originaram mudanças populacionais que reestruturaram e reorganizaram a rede de assentamentos humanos, direcionados em sua maioria para as áreas urbanas. BECKER (1998) afirma ainda que o alto e acelerado crescimento da população urbana transformou a região em uma "floresta urbanizada", que ao mesmo tempo não conta com a implementação de uma infraestrutura necessária para garantir as condições mínimas de qualidade de vidadessa população.

Tabela 2

Amazônia Legal: 1970/2000.Taxa de Crescimento Urbano e Rural (\%)

\begin{tabular}{|c|c|c|c|c|c|c|}
\hline \multirow{2}{*}{$\begin{array}{c}\text { Unidades } \\
\text { De } \\
\text { Federação }\end{array}$} & \multicolumn{3}{|c|}{ Urbana } & \multicolumn{3}{|c|}{ Rural } \\
\hline & $\begin{array}{c}1970- \\
1980 \\
\end{array}$ & $\begin{array}{c}1980- \\
1991 \\
\end{array}$ & $\begin{array}{c}1991- \\
2000 \\
\end{array}$ & $\begin{array}{c}1970- \\
1980 \\
\end{array}$ & $\begin{array}{c}1980- \\
1991 \\
\end{array}$ & $\begin{array}{c}1991- \\
2000 \\
\end{array}$ \\
\hline BRASIL & 4,48 & 3,06 & 2,19 & $-0,61$ & $-0,82$ & $-1,23$ \\
\hline Rondônia & 14,74 & 10,64 & 2,98 & 16,74 & 6,01 & 0,46 \\
\hline Acre & 8,41 & 6,63 & 3,67 & 0,84 & $-0,72$ & 1,64 \\
\hline Amazonas & 7,82 & 5,62 & 3,43 & 0,5 & 0,36 & 1,66 \\
\hline Roraima & 10,72 & 10,89 & 5,87 & 3,17 & 8,97 & 0,12 \\
\hline Pará & 5,08 & 4,36 & 4,66 & 4,52 & 3,6 & $-2,13$ \\
\hline Amapá & 5,25 & 8,18 & 6,14 & 3,41 & $-2,85$ & $-0,54$ \\
\hline Tocantins & 8,19 & 6,01 & 4,93 & 0,94 & $-1,27$ & $-2,67$ \\
\hline NORTE & 6,66 & 5,73 & 4,26 & 3,43 & 2,53 & $-1,05$ \\
\hline Maranhão & 4,82 & 4,5 & 6,16 & 2,54 & 1,32 & $-2,83$ \\
\hline $\begin{array}{l}\text { Mato } \\
\text { Grosso }\end{array}$ & 10,93 & 8,53 & 2,96 & 2,81 & 1,15 & $-0,47$ \\
\hline Goiás & 8,37 & 3,65 & 1,28 & $-2,46$ & $-3,49$ & 0,79 \\
\hline AM. LEGAL & 6,64 & 5,99 & 4,38 & 3,03 & 1,99 & $-1,58$ \\
\hline
\end{tabular}

Os fluxos migratórios que se dirigiram para as áreas urbanas se concentraram principalmente nas capitais dos estados que em 2000 contabilizaram 26\% do total da população da Amazônia Legal.

No período de 1970 a 1980 todos os estados da região norte, com exceção do Pará e Amapá, apresentaram crescimentos populacionais urbanos expressivos e maiores que a média nacional. Rondônia com uma taxa de crescimento urbano de 14,74\%, Roraima (10,72\%) e Mato grosso $(10,93 \%)$, merecem destaque no período.

Entre os anos de 1980 a 1991 a população urbana da região manteve o crescimento expressivo. Os estados de Rondônia, Roraima e Mato Grosso se destacaram novamente pela continuidade das 
maiores taxas, juntamente com o Amapá. Na década seguinte Roraima e Amapá apresentaram as maiores taxas de crescimento urbano, acompanhados pelo Maranhão. $\mathrm{O}$ alto dinamismo e crescimento verificados no estado do Maranhão desde a década de 1980estão relacionados em grande parte com a Ferrovia Carajás-Ponta da Madeira. Este eixo teve papel relevante na organização do espaço maranhense ao favorecer o deslocamento da população migrante intermunicipal, além de contribuir para a implantação de pólos guseiros, distritos industriais, siderurgias e indústrias metalúrgicas de alumínio.

Apesar do crescimento urbano se apresentar como destaque para região, a população rural também apresentou taxas de crescimento positivas, principalmente entre as décadas de 70 e 80 . AMARAL et al, (2001) realça que os principais motivadores desse crescimento foram os programas governamentais de desenvolvimento e instalação de infraestrutura. Além disso, a população rural recebeu migrantes inter-regionais e intra-regionais provenientes principalmente de áreas urbanas, o que estimulou seu crescimento em todos os estados da Amazônia Legal, com exceção dos municípios de Goiás, na década de 70 .

Rondônia foi o estado da Amazônia Legal que apresentou maior crescimento da população rural durante os anos de 1970 a 1991. A divulgação oficial e oficiosa da disponibilidade de terras com solos ricos na Amazônia colaborou para o grande impulso a emigração de áreas brasileiras em crise agrária no sul do país que se destinaram em grande parte para Rondônia (IBGE, 1991).

$\mathrm{Na}$ década de 90 os estados demonstraram menor crescimento, em alguns casos negativo, da população rural. As grandes perdas da população rural são conseqüentes principalmente dos fluxos migratórios campo-cidade, uma vez que o desenvolvimento regional proporcionou atrativos para as áreas urbanas. Esse processo também pode ser observado a partir da evolução da estrutura etária da população rural e urbana da região amazônica nos anos de 1991 e 2000. Nota-se que a redução generalizada de todos os grupos etários da população rural encontra forte correlação com a óbvia expansão da população urbana da região em ambos os anos.

Autores como HOGAN et al (2008) e CAMPARI (2002) discutem que a diminuição da população rural sinaliza a incapacidade do modelo econômico em manter a população no campo, consequentemente a urbanização seria uma contrapartida do processo de concentração de terras rurais.

O esvaziamento do campo e o inchaço das áreas urbanas refletem o aumento do grau de urbanização durante os anos, aumentado a participação da população urbana na população total. A evolução do grau de urbanização na Amazônia Legal acompanhou a tendência brasileira e apesar da variabilidade desse grau dentre os estados, o seu aumento foi comum a todos desde 1970. Em 2000 merecem destaque os estados do Amapá, Mato Grosso, Goiás e Roraima que apresentam em sua população total $75 \%$ de moradores urbanos. 
Segundo HOGAN et al, (2008) "o crescimento da urbanização se deve a grande parte dos movimentos migratórios que das fronteiras terminaram nas cidades”, já que esse processo de ocupação acabou também por confrontar as populações já residentes (seringueiros, ribeirinhos, índios, pequenos posseiros) com aqueles que chegavam. BECKER (2006) afirma que "a urbanização resulta do crescimento dos centros urbanos antigos e do aparecimento de novos", sendo que dentre as antigas cidades, estão às capitais estaduais, mais populosas e urbanizadas que as demais cidades da Amazônia Legal.

Em 2000 mais de 140 localidades da Amazônia Legal passaram a condição urbana, as capitais mais populosas foram Manaus- AM, Belém- PA e São Luís-MA. Juntas essas capitais apresentaram cerca de 3 milhões e 500 mil habitantes, o equivalente a 17\% do total da população da Amazônia Legal.

\subsection{Descrição e Análise da Dinâmica Migratória}

Como descrito anteriormente a Amazônia Legal obteve ganhos populacionais expressivos desde 1970, o que caracterizou altas taxas de crescimento anual maiores que $2 \%$ na última década.

Os saldos migratórios positivos apresentados pela maioria dos estados pertencentes a região nos períodos quinquenais de 1986/1991 e 1995/2000 também comprovam esse comportamento a partir dos dados de migração. A taxa de crescimento anual de 5,99\% da população urbana no período de 1980 a 1991, contra a taxa de $1,99 \%$ da população rural permite concluir que a maioria dos imigrantes que se destinaram para a Amazônia Legal responsáveis pelos saldos positivos do quinquênio de 1986/1991 se dirigiram para as áreas urbanas. Comparadas as taxas de crescimento anual urbana e rural do período de 1991 a 2000 é possível interpretar o mesmo processo em relação ao quinquênio de 1995/2000. Nesse contexto Amaral (2003) afirma que "na segunda metade dos anos 80 e nos anos 90 as migrações para a região foram exclusivamente urbanas, sendo compostas em boa parte por migrantes que se deslocaram anteriormente para a zona rural” (pg.11)

Apesar da predominância dos ganhos populacionais não são todos os estados da Amazônia Legal que colaboram para os seus saldos positivos. Dentre os estados do Norte, durante o quinquênio de 1986/1991, o Acre foi o único estado que apresentou perda populacional, com um saldo negativo de aproximadamente mil emigrantes. O estado que destacou pelas altas perdas populacionais nesse quinquênio foi o Maranhão, com cerca de 134 mil emigrantes a mais em relação ao número de imigrantes. O saldo negativo do Maranhão, se constitui em um dos maiores pesos nos fluxos de emigrantes da Amazônia Legal e da região nordeste. 
Tabela 3

\begin{tabular}{|c|c|c|c|c|c|c|}
\hline \multirow{3}{*}{$\begin{array}{c}\text { Regiões e } \\
\text { Unidades de } \\
\text { Fedração } \\
\end{array}$} & \multicolumn{6}{|c|}{ Volumes segundo periodos Qüinqūenais } \\
\hline & \multicolumn{3}{|c|}{ 1986-1991 } & \multicolumn{3}{|c|}{$1995-2000$} \\
\hline & IMI & EMI & Saldo & IMI & EMI & Saldo \\
\hline Rondônia & 126.930 & 94.266 & 32.664 & 83.325 & 72.734 & 10.591 \\
\hline Acre & 12.970 & 14.321 & -1.351 & 13.635 & 16.069 & -2.434 \\
\hline Amazonas & 59.301 & 44.257 & 15.044 & 89.626 & 58.658 & 30.968 \\
\hline Roraima & 35.323 & 6.693 & 28.630 & 47.750 & 14.380 & 33.370 \\
\hline Pará & 212.396 & 183.094 & 29.302 & 182.045 & 234.231 & -52.186 \\
\hline Amapá & 23.641 & 7.117 & 16.524 & 44.582 & 15.113 & 29.469 \\
\hline Tocantins & 82.316 & 71.804 & 10.512 & 95.430 & 82.513 & 12.917 \\
\hline NORTE & 552.877 & 421.552 & 131.325 & 556.393 & 498.680 & 57.713 \\
\hline Maranhão & 103.329 & 237.866 & -134.537 & 100.820 & 274.740 & -173.920 \\
\hline NORDESTE & 936.954 & 1.813 .063 & -876.109 & 1.055 .924 & 1.819 .854 & -763.930 \\
\hline $\begin{array}{l}\text { Mato } \\
\text { Grosso }\end{array}$ & 226.891 & 117.759 & 109.132 & 166.297 & 123.726 & 42.571 \\
\hline Goiás & 268.017 & 156.611 & 111.406 & 372.702 & 169.887 & 202.815 \\
\hline C. OESTE & 813.726 & 522.730 & 290.996 & 825.908 & 590.902 & 235.006 \\
\hline SUDESTE & 2.151 .415 & 1.511 .523 & 639.892 & 2.120 .563 & 1.662 .152 & 458.411 \\
\hline SUL & 551.923 & 738.027 & -186.104 & 610.354 & 629.554 & -19.200 \\
\hline
\end{tabular}

A região norte com um saldo positivo de 130 mil migrantes teve como maiores contribuições os altos fluxos de imigrantes que se destinaram para Rondônia e Pará. No quinquênio de 1995/2000 a maioria dos estados que compõem a Amazônia legal permaneceram com a mesma tendência, ou seja, apresentou ganhos populacionais, apesar dos menores saldos migratórios, o que significa uma diminuição da diferença entre o número de imigrantes e de emigrantes.

A grande diminuição do saldo positivo da Amazônia Legal se deve as grandes perdas do estado do Maranhão e do Pará que também teve o maior peso nas perdas populacionais da região Norte no quinquênio de 1995/2000. Em relação aos fluxos inter-regionais, as regiões sudeste, centro-oeste e norte permanecem com os ganhos populacionais em detrimentos dasperdas da região nordeste e sul nesse quinquênio.

\subsection{Descrição e Análise da expectativa de vida, mortalidade e fecundidade}

As taxas de fecundidade total dos estados da região norte acompanham a tendência nacional de redução. Desde a década de 90 até o ano de 2007 a taxa da região diminuiu 34\% e com essa redução as mulheres em idade reprodutiva passaram a ter atualmente cerca de 2,4 filhos. Apesar da diminuição, as taxas de fecundidade da região norte sempre foram maiores que a média nacional. Segundo MOREIRA (1996) as taxas de fecundidade total da Amazônia Legal sempre foram elevadas, e durante o período de 1950 a 1970 eram as taxas mais altas do país. A região nordeste também acompanha a região norte nas elevadas taxas de fecundidade total, se comparadas com as regiões polo econômicas do país, sudeste e sul. 


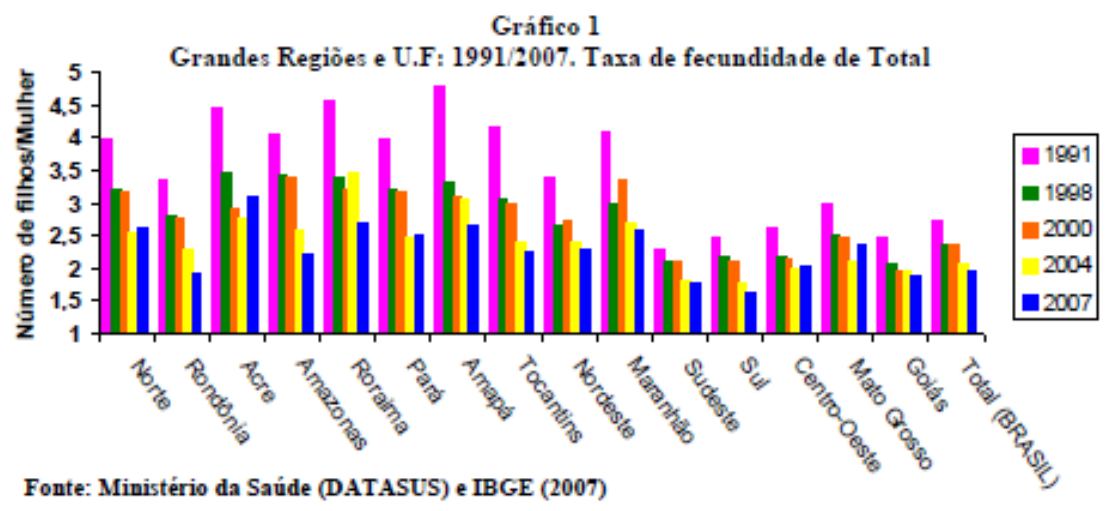

Em 1991 os estados do Acre, Roraima, Amapá e Maranhão, foram os que apresentaram as maiores taxas de fecundidade total da Amazônia Legal com cerca de 4 filhos por mulher em idade reprodutiva, cerca de duas vezes maior que TFT nacional. Nos anos posteriores esses estados também foram destaques, juntamente com o Amazonas nos anos de 1998 e 2000. Os estados que sofreram maiores reduções na TFT, entre os anos de 1991 a 2007, foram Amazonas e Tocantins que diminuíram suas taxas em $45 \%$.

A diminuição da fecundidade total é consequente de algumas transformações sociais e econômicas que acompanharam o desenvolvimento regional. Essas transformações articulam, por exemplo, a inserção cada vez mais efetiva da mulher no mercado de trabalho, e a melhoria na infraestrutura e dos setores de comunicação. Além disso, a urbanização recente cria um cenário com outros pesos econômicos relativos à criação dos filhos, normalmente mais caros, o que alerta a população das dificuldades da manutenção familiar.

Assim como a fecundidade a mortalidade infantil também diminuiu na região norte. Em 1998 morriam cerca de 31 crianças dentre mil nascidas vivas, já em 2007 esse númeropassou para 25 crianças. Apesar das quedas da taxa de mortalidade infantil, percebe-se também a superioridade dessas taxas em relação à média nacional, e a média das regiões sudeste e sul. Enquanto na região norte em 2004 morriam 28 crianças (por mil nascidas vivas), na região sul morriam 10 crianças a menos. Em contrapartida as taxas da região norte. 


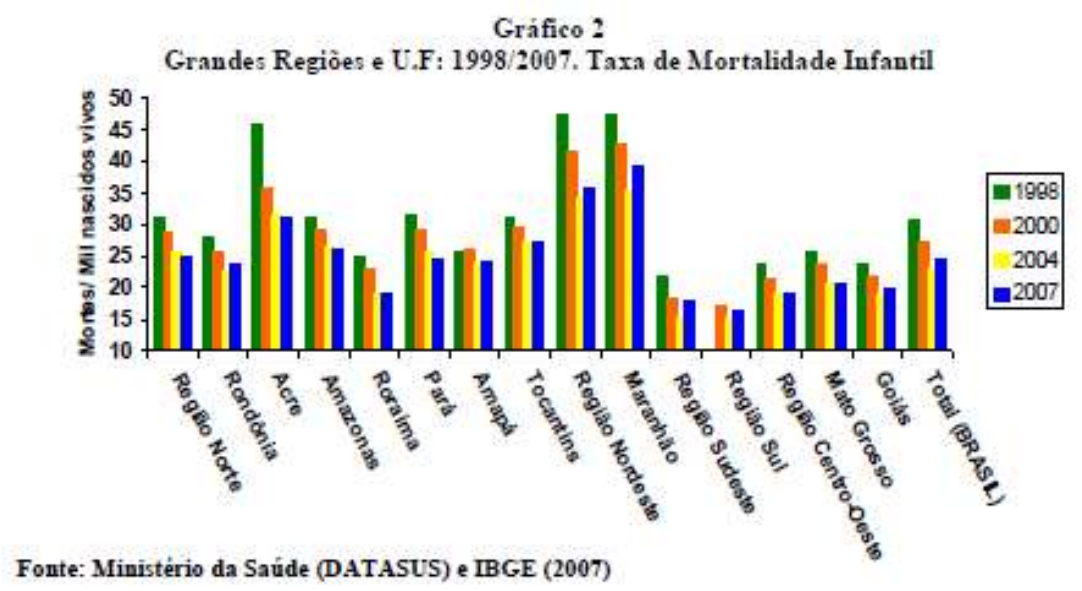

A redução das taxas de mortalidade infantil, além de ser um reflexo das próprias quedas das taxas de fecundidade, é resultante de investimentos nos setores de saúde que propiciam maior cobertura vacinal da população e aumento da cobertura do pré-natal.

A redução da mortalidade na Amazônia Legal, também ocorre para todos os grupos etários. Ao longo dos anos de 1991 a 2007 a taxa bruta de mortalidade dos estados da região norte e das outras unidades pertencentes à Amazônia Legal apresentaram contínuas reduções.

As quedas na taxa de mortalidade condicionam por sua vez o aumento da esperança de vida da população. A região norte durante os anos de 1991 a 2007 experimentou um aumento da esperança de vida, com índices aproximados da média nacional e da região nordeste, porém um pouco distantes das regiões centro-sul.

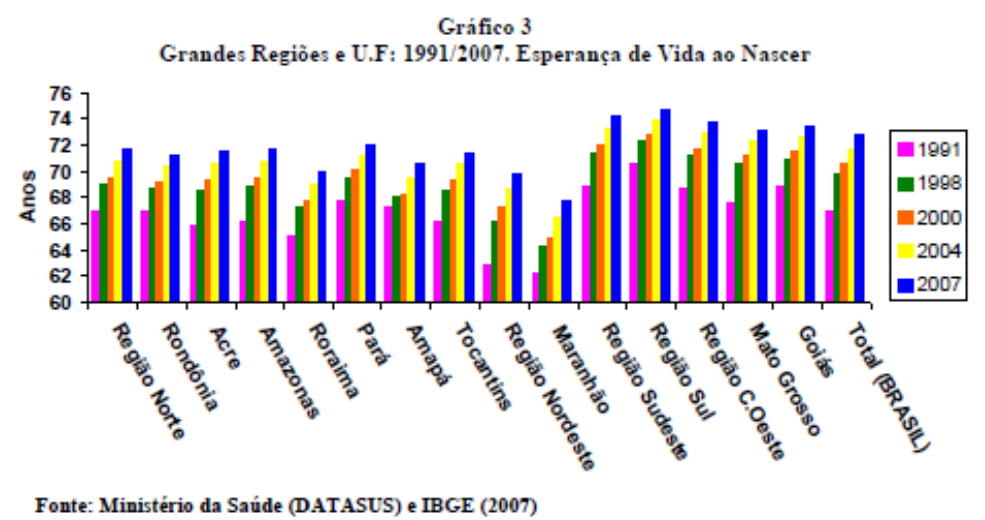

O Estado do Pará, juntamente com as unidades da região centro-oeste que possuem municípios na Amazônia Legal (Mato Grosso e Goiás) foram os que apresentaram as maiores expectativas de vida da região Amazônica na década passada, alcançando em 2007 expectativas maiores ou iguais a 72 anos. 
O aumento da expectativa de vida e diminuição da mortalidade na região amazônica indicam melhorias nos serviços básicos que promovem o desenvolvimento humano (saúde, educação, etc.). Em relação à dinâmica demográfica, se as quedas tanto da fecundidade como da mortalidade se mostrarem contínuas, poderemos considerar que "o crescimento vegetativo será cada vez menos importante como impulsor da mudança demográfica” na Amazônia Legal (HOGAN et al,, 2008).

\section{4- PROJEÇÃO DA POPULAÇÃO RESIDENTE NA AMAZÔNIA LEGAL: 2005-2050}

Para elaboração das projeções populacionais dos municípios que integram a Amazônia Legal utilizou-se, primeiramente, o método de extrapolação do crescimento populacional observado entre os anos 2000 e 2009 para realização das estimativas dos anos de 2005 e 2010. Posteriormente para as estimativas dos demais anos (2015 a 2050) empregou-se o método AiBi. Esse método, como descrito anteriormente, necessita de projeções populacionais de uma maior área - que, neste caso, foram às projeções do Brasil - para os anos correspondentes as projeções das áreas menores - municípios amazônicos. Para a projeção populacional dos municípios da Amazônia Legal foram utilizados, portanto, os resultados da projeção do IBGE, Revisão 2008 (IBGE,2008).

A partir do gráfico de dispersão 8 que representa as projeções municipais é possível visualizar a relação entre as estimavas elaboradas e aquelas fornecidas pelo IBGE (Revisão 2008). Nota-se no gráfico que as projeções próprias estão em concordância com aquelas do IBGE (2008), o que é demonstrado pelo valor de $\left(\mathrm{R}^{2}\right)$ próximo de 1.

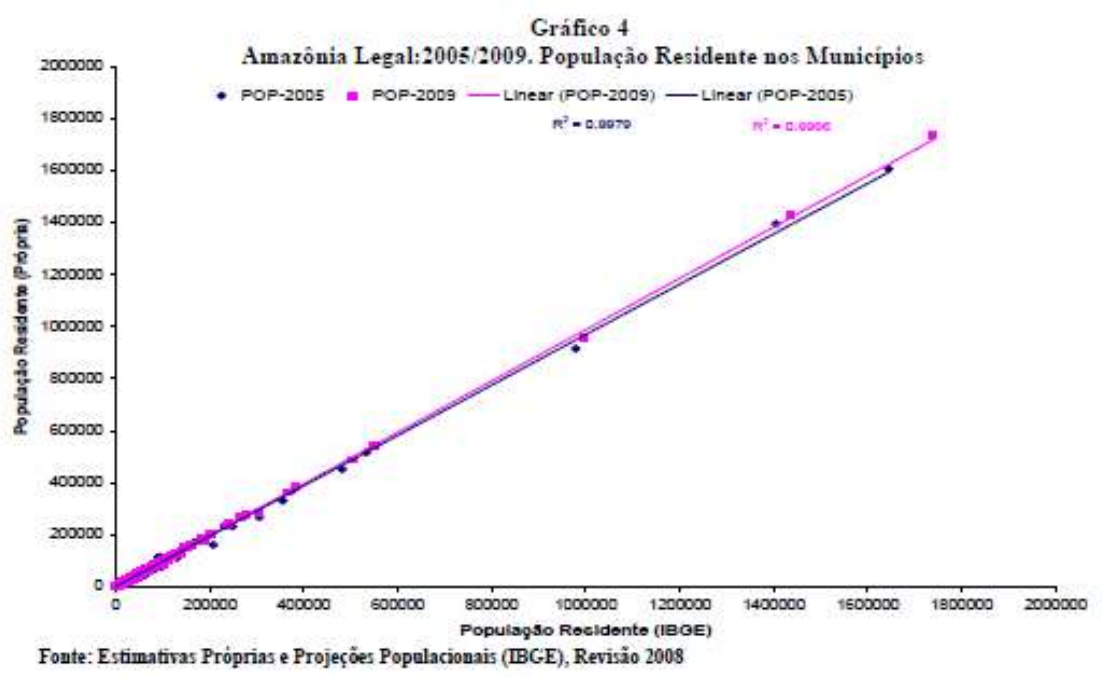

\subsection{Evolução da População por sexo e situação de domicilio}


As projeções populacionais demonstram que a população da Amazônia Legal terá crescimento contínuo até meados da década de 40, período que o contingente populacional da região alcançará um número 48\% maior que a população de 2000. A partir de 2045 com a redução do crescimento essa diferença cairá para 44\% e para 41\% em 2050, ano em que apopulação terá número aproximado ao da década de 30 com cerca de 28, 9 milhões de habitantes.

O processo de urbanização da Amazônia Legal evidenciado pelo alto crescimento da população urbana durante o período de 1970 a 2000 se mostra contínuo também para os anos projetados. Em todo o período de 2005 a 2050 a população urbana apresentará mais que o dobro do número de habitantes em relação a população rural. Essa diferença será mais acentuada entre os anos de 2005 e 2010 e posteriormente a partir da década de 30 - período em que a população urbana apresentará cerca de $137 \%$ a mais de indivíduos em relação a população rural.

Os estados de Rondônia, Pará, Amazonas, Maranhão e Mato Grosso irão contribuir com mais de 60\% para a população urbana da Amazônia Legal em todos os anos projetados. Esse índice se deve aos contingentes dos municípios das capitais e outros de porte médio como Jarú - RO, Parintins - AM, Imperatriz- MA, Várzea Grande - MT. Os municípios que mais irão incrementar a população rural da Amazônia Legal pertencem principalmente aos estados do Maranhão e Pará, dentre eles destacam-se: Paço do Limiar - MA, São José do Ribamar - MA, Santarém - PA e Cametá - PA.

Tabela 4

\begin{tabular}{|c|c|c|c|c|}
\hline \multirow[b]{2}{*}{ POPULACุÂO } & \multicolumn{2}{|c|}{2.005} & \multicolumn{2}{|c|}{2.010} \\
\hline & Urbana & Rural & Urbana & Rural \\
\hline Total & 16.179 .682 & 6.775 .030 & 17.414 .311 & 7.294 .811 \\
\hline Masculina & 7.987 .133 & 3.652 .360 & 8.759 .517 & 4.001 .886 \\
\hline \multirow[t]{2}{*}{ Feminina } & 8.204 .896 & 3.109 .803 & 8.663 .555 & 3.283 .633 \\
\hline & \multicolumn{2}{|c|}{2.015} & \multicolumn{2}{|c|}{2.020} \\
\hline POPULAÇÂO & Urbana & Rural & Urbana & Rural \\
\hline Total & 18.382 .828 & 7.712 .257 & 19.177 .758 & 8.054 .828 \\
\hline Masculina & 9.364 .663 & 4.285 .898 & 9.858 .157 & 4.517 .603 \\
\hline \multirow[t]{2}{*}{ Feminina } & 9.023 .791 & 3.420 .261 & 9.322 .782 & 3.533 .561 \\
\hline & \multicolumn{2}{|c|}{2.025} & \multicolumn{2}{|c|}{2.030} \\
\hline POPULAÇÂO & Urbana & Rural & Urbana & Rural \\
\hline Total & 19.848 .906 & 8.344 .087 & 20.354 .175 & 8.561 .846 \\
\hline Masculina & 10.272 .700 & 4.712 .371 & 10.581 .198 & 4.857 .488 \\
\hline \multirow[t]{2}{*}{ Feminina } & 9.577 .406 & 3.630 .090 & 9.772 .788 & 3.704 .149 \\
\hline & \multicolumn{2}{|c|}{2.035} & \multicolumn{2}{|c|}{2.040} \\
\hline POPULAÇÂO & Urbana & Rural & Urbana & Rural \\
\hline Total & 20.637 .880 & 8.684 .129 & 20.692 .547 & 8.707 .706 \\
\hline Masculina & 10.748 .237 & 4.936 .322 & 10.769 .866 & 4.946 .987 \\
\hline \multirow[t]{2}{*}{ Feminina } & 9.888 .921 & 3.748 .148 & 9.922 .205 & 3.760 .754 \\
\hline & \multicolumn{2}{|c|}{2.045} & \multicolumn{2}{|c|}{2.050} \\
\hline POPULAÇÂO & Urbana & Rural & Urbana & Rural \\
\hline Total & 20.541 .864 & 8.642 .763 & 20.211 .668 & 8.500 .432 \\
\hline Masculina & 10.662 .468 & 4.897.129 & 10.441 .699 & 4.794 .125 \\
\hline Feminina & 9.879 .892 & 3.744 .719 & 9.772 .042 & 3.703 .867 \\
\hline
\end{tabular}




\subsection{Projeções Populacionais dos Municípios da Amazônia Legal: 2005 a 2050}

Apesar da elaboração das estimativas quinquenais (2005 a 2050), serão representadas espacialmente, apenas as populações dos anos de 2010, 2030 e 2050, que são suficientes para efeito de análise e comparação dos dados, já que não houve expressivas variações no comportamento da população durante os 45 anos projetados. Uma análise geral dos mapas permite concluir que cerca de $37 \%$ dos municípios não apresentarão mais de 10.000 habitantes para os anos projetados. Os municípios com mais de 50.000 habitantes não passam de 13\% do total e as maiores populações se concentrarão nas capitais (Belém- PA. Manaus - AM, Cuiabá - MT, Palmas - TO, e São Luiz - MA) que serão os únicos municípios que terão população maior que 500.000 habitantes. O município de Ananindeua-PA também irá se integrar a essa classe a partir de 2015.

O mapa 2 demonstra que os municípios com menor população se concentram no Mato Grosso, Tocantins, norte do estado de Roraima e Amapá. Dentre eles destacam-se: Oliveira de Fátima - TO, Chapada de Areia - TO, Serra Nova Dourada- MT, Nova Marilándia - MT, Rio da Conceição TO, todos com menos de 2.000 habitantes. Os municípios que possuem entre 15.000 a 50.000 habitantes estão concentrados nos estados do Amazonas, Acre e Rondônia.

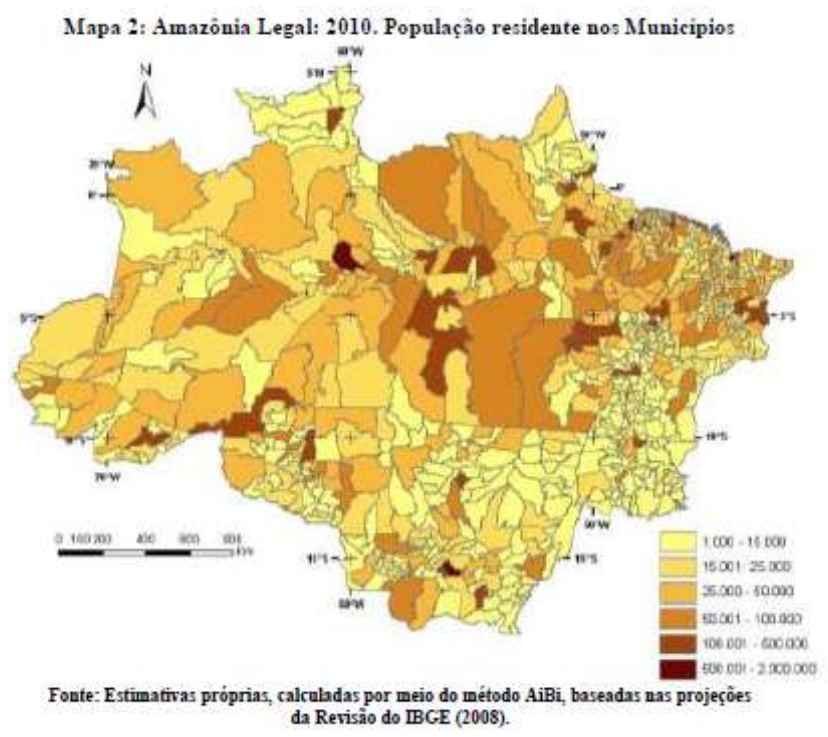

No mapa 3, onde esta representada a população de 2030, é possível observar a variação de classe para alguns municípios, principalmente os que apresentarão mais de 80.000 habitantes entre os anos de 2005 a 2020, como Altamira- PA e Santa Inês - MA e que em 2030 terão mais de 100.000 habitantes. Em geral a distribuição se apresenta a mesma que em 2010, com predominância de municípios com as maiores populações nas regiões centro - norte e nordeste da Amazônia Legal. 
A redução constante do crescimento populacional resultará em taxas negativas para a maioria dos municípios no período de 2035 a 2050. Apesar da variação no tamanho da população para grande parte dos municípios, que em 2050 apresentarão número menor dehabitantes em relação a década anterior, essa redução não será significativa.

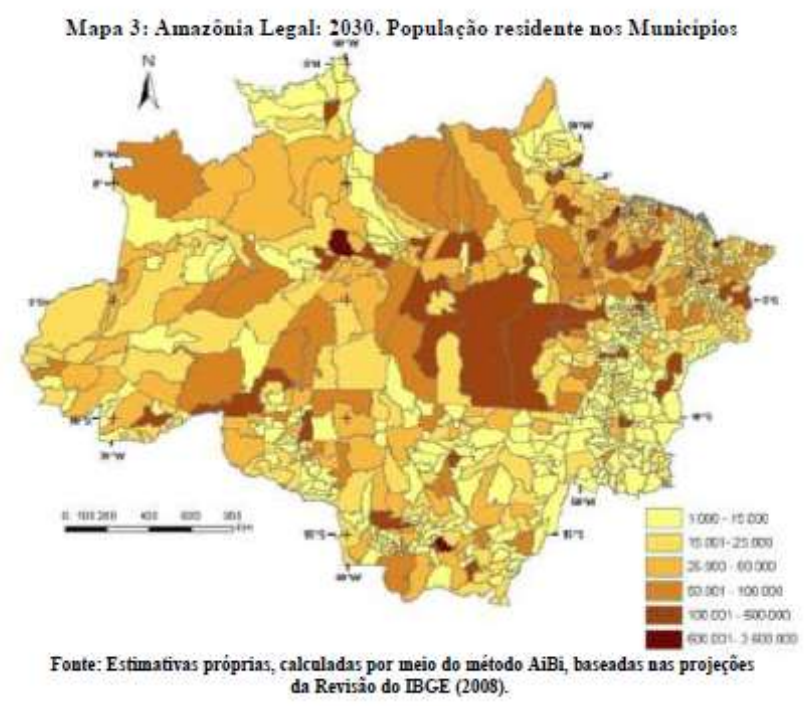

Como pode ser observado no mapa 4, a diminuição do crescimento no período será suficiente para mudar alguns municípios para classes de menores tamanho de população, se comparadas as suas posições em 2030. Alguns exemplos são os municípios de Capixaba - AC e Bonito- PA.

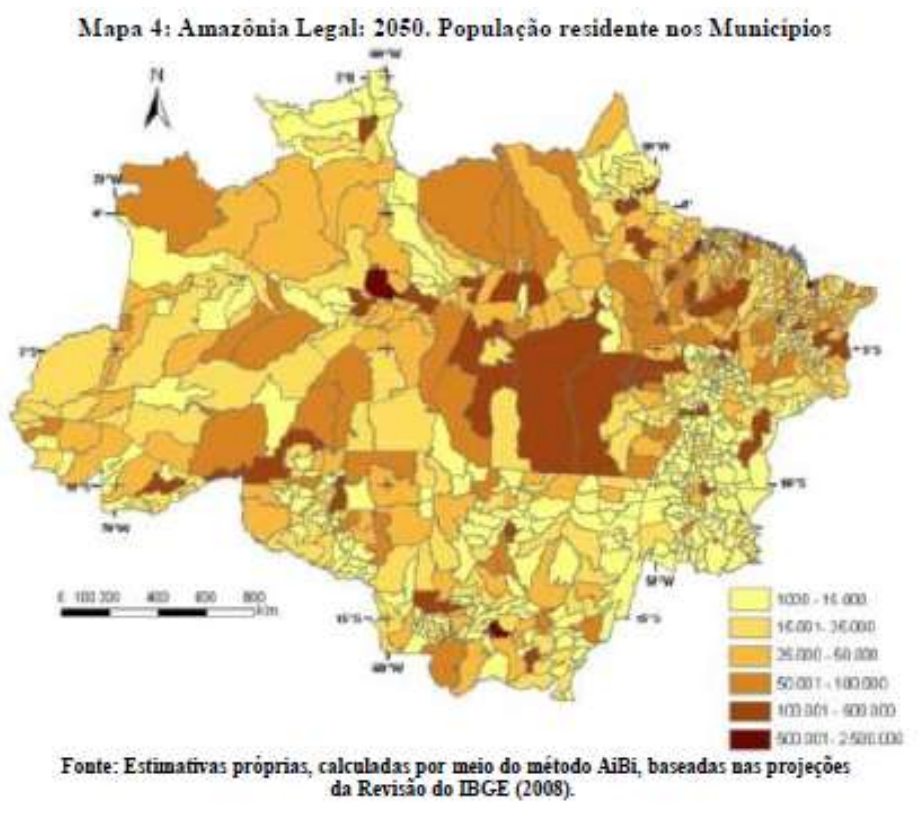

\subsection{Evolução da Taxa de Crescimento Populacional Anual dos Municípios}


Os mapas 5,6 e 7 representam a evolução da taxa de crescimento anual da população residente nos municípios amazonenses. O mapa 5 mostra esse crescimento futuro para o período de 2005 a 2020. Durante esses anos cerca de $90 \%$ dos municípios iram apresentar crescimento positivo e desse total $56 \%$ cresceram a uma taxa maior que 1\%. A maioria dos municípios que irão apresentar as maiores taxas de crescimento anual nesse período, com índices superiores a 4\%, pertencem aos estados do Mato Grosso, Pará e Rondônia. Dentre eles destacam-se, Colniza - MT, Canaó dos Carajás- PA, Aripuaná-MT, Anapú -PA, Paruapebas- PA, Santa Cruz do Xingu-MT e Santa Rita do Trivelato - MT.

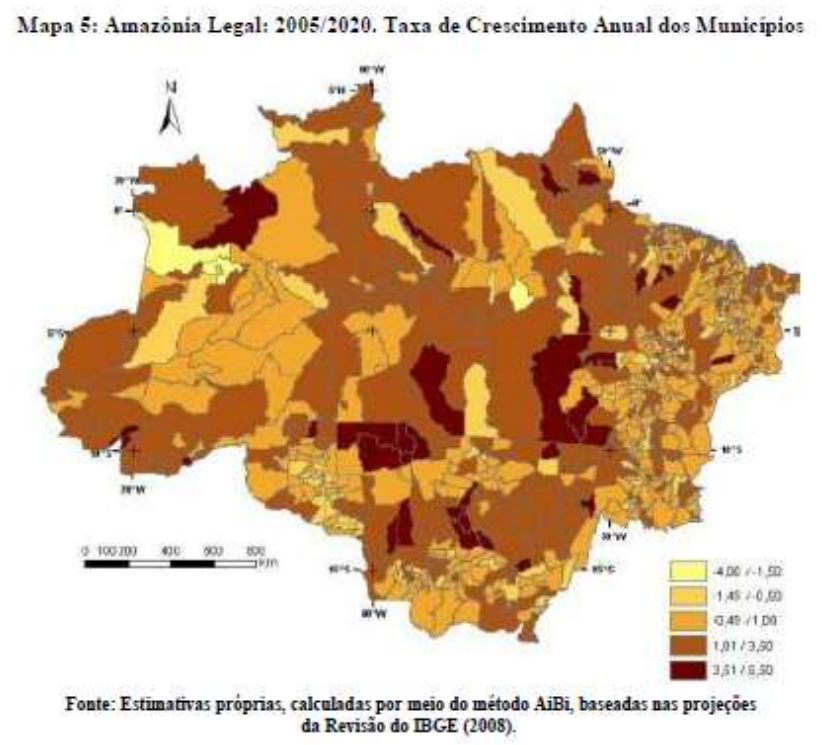

As maiores perdas populacionais ocorreram nos municípios de Uriará-PA, Japurá - AM, Brejo de Areia - MA, Fonte Boa - AM, São Raimundo do Doca Bezerra - MA e Junco do Maranhão - MA. Todos apresentaram altas taxas negativas menores que $-2 \%$.

No período de 2020 a 2035, apesar do crescimento positivo permanecer constante para cerca de 90\% dos municípios da Amazônia Legal, as taxas se apresentarão muito inferiores em relação ao período passado. Os mesmos municípios se destacarão pelas maiores taxas de crescimento, no entanto, essas taxas não terão valores maiores que $2 \%$. Nota-se, portanto, que esse período será uma fase de transição na qual os municípios apresentarão altas reduções do crescimento populacional que culminará em taxas negativas no período seguinte. A redução contínua terá como resultado a predominância de taxas negativas entre os anos 2035 a 2050, como pode ser observado no mapa 6.

Ao contrário do que ocorrerá nos períodos anteriores, entre os anos de 2035 a 2050, o crescimento da população de $90 \%$ dos municípios será negativo. As taxas não irão variar muito, praticamente todos os municípios que apresentaram crescimento positivo, terão uma taxa de $0,08 \%$ contra o menor crescimento da taxa do município Colniza -MT igual a $-0,45 \%$. 


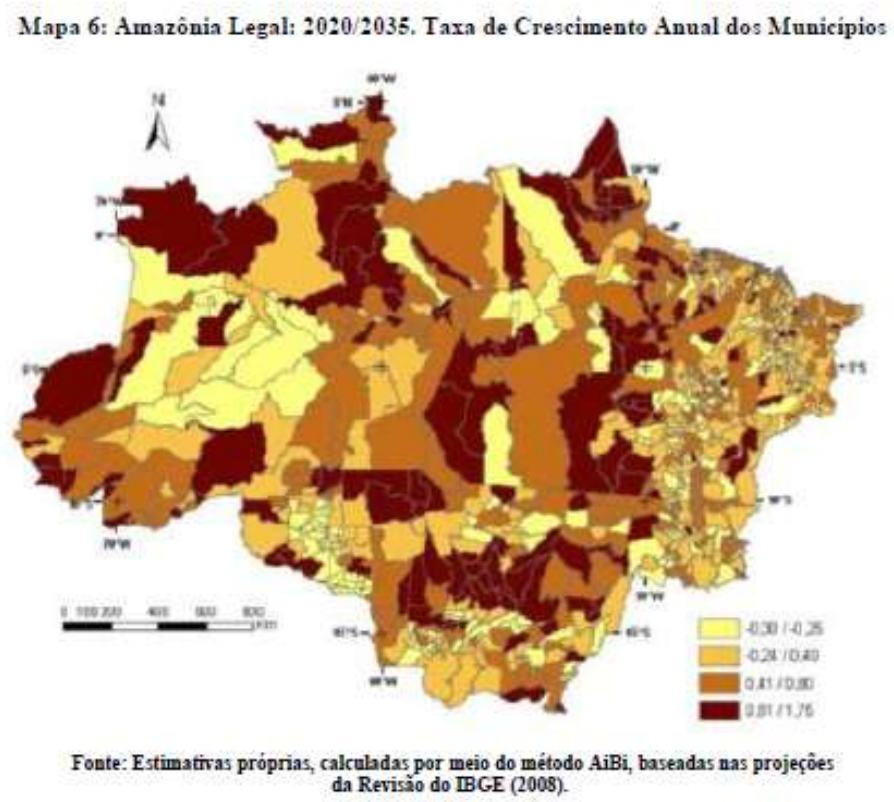

A diferença mais significativa e instigante dos dados é que os municípios que apresentarão maiores crescimentos, como no caso de Colniza -MT nos períodos anteriores irão apresentar no período de 2035 a 2050 as maiores taxas negativas da região. Conforme as estimativas elaboradas muitos municípios que nos anos de 2005 a 2035 se caracterizarão como repulsores de população, irão apresentar como atrativos a partir desse último ano.

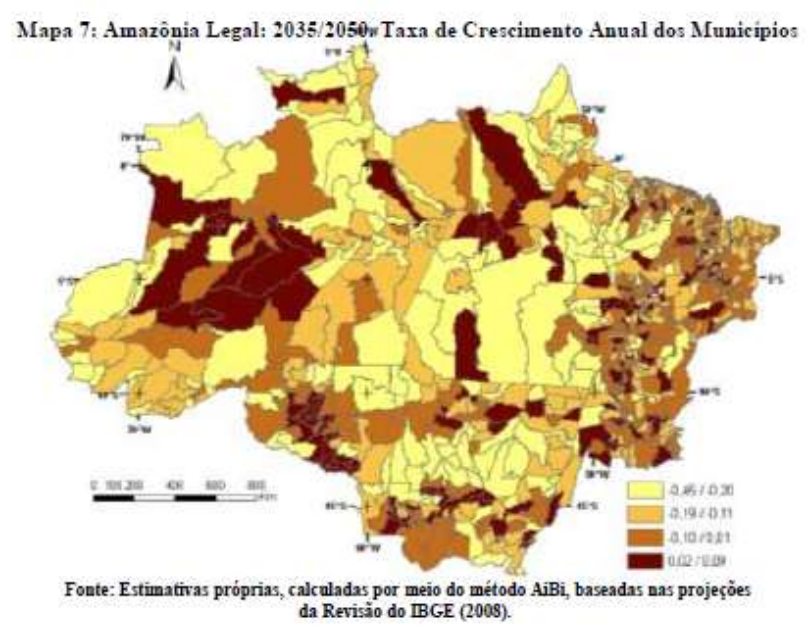

4.3. Distribuição Espacial da População dos municípios que integram a Amazônia Legal

As análises da distribuição espacial da população dos municípios foram realizadas a partir dos mapas 8, 9 e 10 que correspondem as projeções populacionais de 2010, 2030 e 2050 respectivamente. 
Os mapas de distribuição representam de forma mais clara o comportamento já verificado nos mapas de população residente. Dessa forma nota-se nos três mapas a tendência de uma concentração populacional nas regiões nordeste, centro - norte, sule sudoeste da Amazônia, mais especificamente nos estados do Pará, Maranhão, Tocantins, alguns municípios em Rondônia, norte do Amazonas, Mato Grosso, e Acre. Essa tendência é esperada uma vez que se processa nos pólos econômicos de atração da Amazônia Legal, que incluem, por exemplo, as grandes capitais, Belém, Manaus, São Luiz e Palmas.

Grande parte dos estados do Amazonas, Acre, Roraima, Amapá e Mato Grosso constituirão as principais áreas vazias de população. Nota-se um adensamento da população em 2030 (mapa 9), consequente do crescimento continuo, porém com maior intensidade em torno das mesmas áreas concentradas. O mesmo ocorrerá com a população em 2050 (mapa 10), que reduzida, devido ao crescimento negativo tendencial desde 2045, apresenta um contingente aproximado ao da população de 2030.

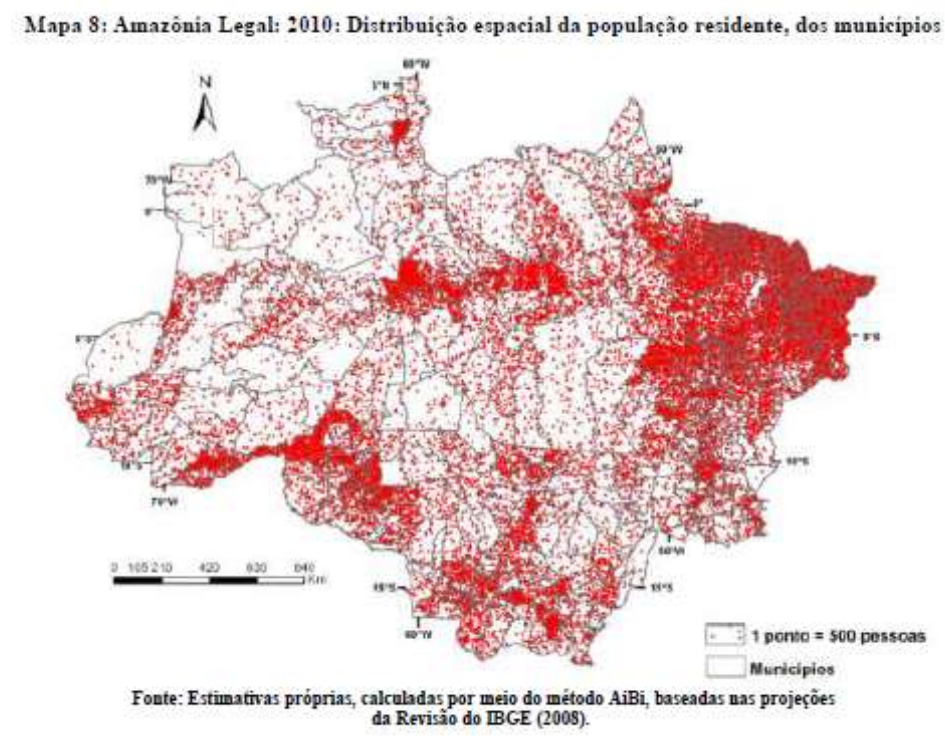




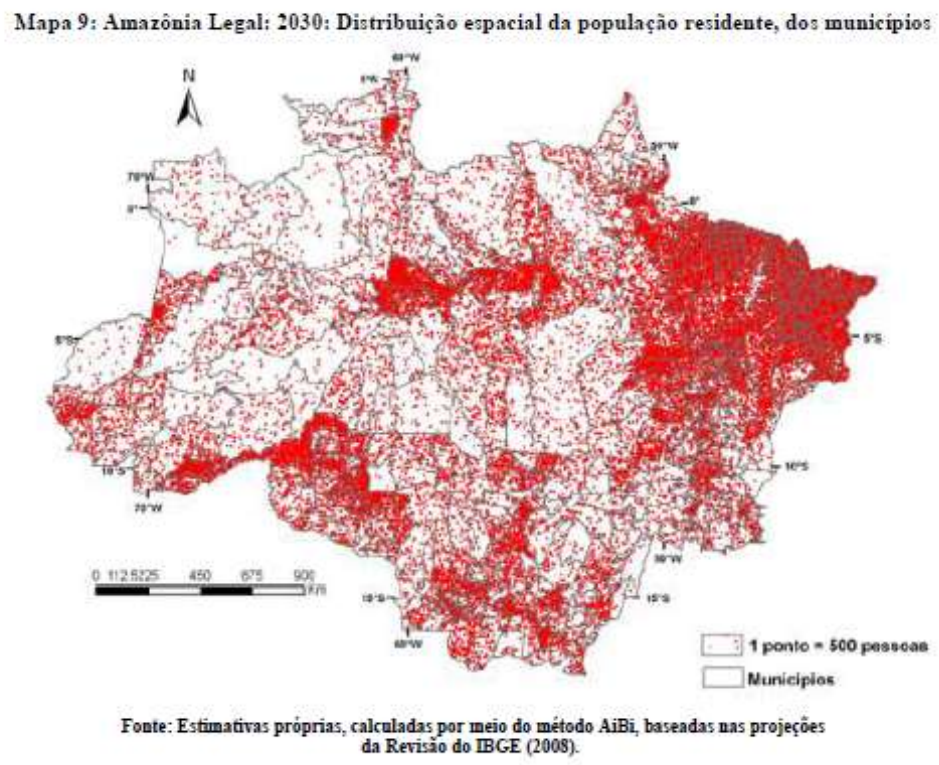

Mapa 10: Amazônia Legal: 2050: Distribuição espacial da população residente, dos municipios

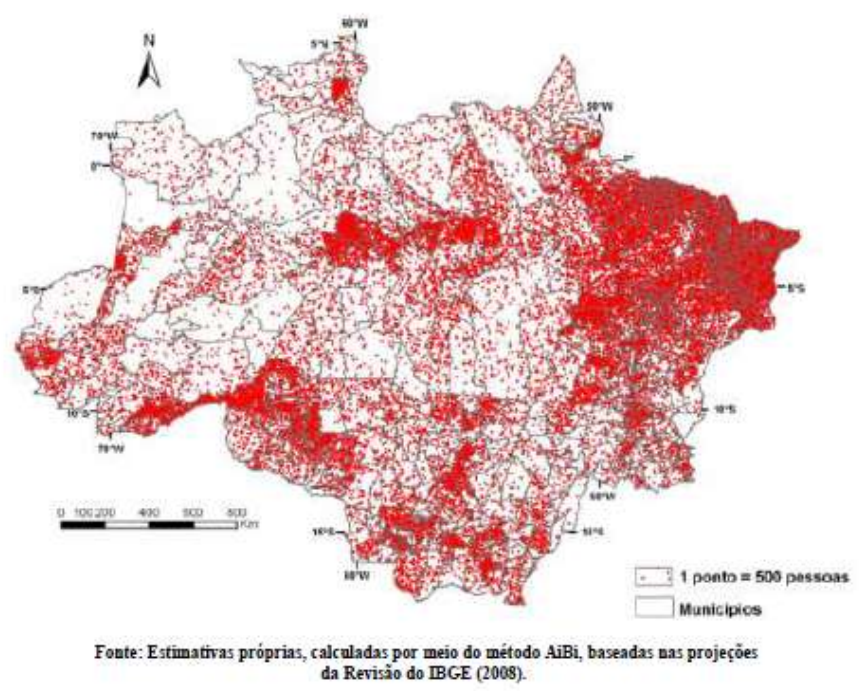

\section{5 - CONSIDERAÇÕES FINAIS}

A população da Amazônia Legal, à semelhança do que ocorre em todo o país, experimenta um forte declínio nos níveis de fecundidade e mortalidade, o que torna o crescimento vegetativo cada vez menos importante como impulsor da mudança demográfica. Em outras palavras o crescimento vegetativo regional será incapaz por si só de promover um crescimento populacional suficiente para ampliar de forma significativa a expansão da densidade demográfica da região, caso esses indicadores continuem declinando. 
Apesar da menor influência do crescimento vegetativo, as projeções populacionais realizadas a partir dos estoques regionais demonstram um crescimento constante da população até meados da queda de 40. Entre os anos 2005 a 2020, inclusive, a região apresenta um crescimento mais elevado do que o esperado, invertendo a tendência de desaceleração experimentada pelas taxas de crescimento da primeira metade da década de 90 . No entanto esse crescimento não resultará em uma significativa expansão espacial da presença humana na região que apresentará, conforme os mapas analisados, semelhante distribuição desde o ano 2000.

As restrições a expansão populacional serão ainda mais ampliadas, uma vez que as estimativas apontam para a continuidade do acelerado processo de urbanização da população amazônica - fator preocupante em relação a qualidade ambiental da região. Desde 1970 a maior parcela do incremento da população urbana regional se localizou no grupo de cidades de 100.000 a 500.000 habitantes. Nota-se que essa característica tende a permanecer para os anos projetados que demonstram maior concentração da população nas capitais estaduais e em alguns núcleos de médio porte. As populações rurais continuaram apresentando incrementos muito modestos, quando não taxas de crescimentos negativos para grande parte dos municípios. Esses cenários supõem que futuramente a população continuará a optar preferencialmente em manter-se em núcleos que desfrutam de uma razoável infraestrutura de serviços sociais, o que pressupõe também a manutenção dos movimentos migratórios do tipo rural-urbano.

Os dados, portanto, demonstram a estrita relação entre crescimento urbano e devastação do bioma, perspectivas já defendidas por autores como HOGAN et al (2008), AMARAL (2003) e BECKER (2006). Os autores salientam ainda sobre a futura desconcentração populacional para núcleos de menor população. De fato os dados demonstram uma desconcentração gradual experimentada pela região Amazônica, em que 55\% da população pertencerá aos municípios com menos de 50.000 habitantes em 2050, no entanto nota-se ainda uma concentração majoritária nos núcleos médios.

De um modo geral os novos possíveis pólos de dinamismo regional gerados a partir dos investimentos em infraestrutura na região amazônica dificultam previsões baseadas em eventos passados. Uma nova rodovia, hidrelétrica, e outros processos podem ocorrer na região de forma imprevisível, condicionando outras dinâmicas econômicas e demográficas contraditórias as tendências indicadas pelos dados. As projeções, portanto, aqui elaboradas deveram ser ajustadas sempre que elementos novos se manifestarem, fazendo com que as variações das tendências atuais dos componentes demográficos sejam alteradas.

A preocupação em relação ao futuro da região emerge do cenário atual que indica uma contínua expansão da fronteira agrícola e o desenvolvimento de novos pólos econômicos que conduziram outras 
formas de ocupação e devassamento do bioma. Afetar essas tendências demanda políticas deliberadas de planejamento e de intervenção do setor público sobre os rumos das ocupações futuras da Amazônia Legal.

\section{5- REFERÊNCIAS BIBLIOGRÁFICAS}

AMARAL, Silvana. Geoinformação para estudos demográficos: Representação Espacial de Dados de População na Amazônia Brasileira. Tese de Doutorado. Escola Politécnica da USP. 2003. Disponível em: www.dpi.inpe.br (Acessado em 05/03/2010)

AMARAL, Silvana; CÂMARA, Gilberto; MONTEIRO, Antônio Miguel Vieira. Análise Espacial do Processo de Urbanização da Amazônia. Relatório Técnico. INPE. Dezembro, 2001. Disponível em: www.inpe.br (Acessado em 01/03/2010)

BECKER, B. K. . Amazônia - Geopolítica na Virada do III Milênio. Rio de Janeiro: Editora Garamond, 2006. v. 1. 172 p.

BECKER, B. K. . Dinâmica Urbana na Amazônia. In: Diniz, C. C.; Lemos, M. B.. (Org.). Economia e Território. Belo Horizonte: CEDEPLAR, 2005, v., p. 401-428.

BECKER, B. K. . Síntese do Processo de Ocupação da Amazonia - Lições do Passado e Desafios do Presente. In: Fleischfresser, V.. (Org.). Causas e Dinâmica do Desmatamento naAmazonia. Brasília: MMA, 2001, v. 1, p. 5-28.

BECKER, B. K. Revisão das políticas de ocupação da Amazônia: é possível identificar modelos para projetar cenários? Revista Parcerias Estratégicas. n. 12, setembro de 2001.

BECKER. B. K. Geopolítica da Amazônia, Rio de Janeiro, 1982.

CARVAlHO, J. A. M., GARCIA, R. A. Projeção anual da população das unidades de planejamento (up's) do município de Belo Horizonte, segundo sexo e idade simples, entre 2000 e 2010. In: LEMOS, M. B., DINIZ, C. C. CARVALHO, J. A. M., SANTOS, F.Belo Horizonte no Século XXI. Belo Horizonte: Cedeplar/ UFMG, 2004. Disponívelem:http://www.cedeplar.ufmg.br/pesquisas/projeto_pbh_sec._xxi.php. (Acessado em05/03/2010).

CARVALHO, J. A. M ; GARCIA, Ricardo Alexandrino . O envelhecimento da população brasileira: um enfoque demográfico. Cadernos de Saúde Pública (FIOCRUZ), Rio deJaneiro, v. 19, n. 3, p. 725$733,2003$.

DATASUS. Departamento de Informática do SUS. Indicadores de Dados Básicos -2007. Ministério da Saúde. In: http://www.datasus.gov.br/idb (Acessado em 10/03/2010)

GARCIA, R.A; SOARES-FILHO, B.S. Um sistema de dinâmica demográfica para os municípios Amazônicos. Texto para discussão (248). Belo Horizonte: UFMG/Cedeplar,2005.

HOGAN. Daniel Joseph; D’Antona. Álvaro de O. CARMO. Roberto Luiz. Dinâmica Demográfica Recente da Amazônia. In: Amazônia: Natureza e Sociedade emTransformação. SP. Editora da Universidade de São Paulo.p.71-116.2008. 
IBGE, Censo Demográfico de 1970, 1980, 1991 e 2000. Rio de Janeiro: IBGE, sd. (Disponível em CD$\mathrm{ROM})$.

IBGE, Estimativas de População. Rio de Janeiro: IBGE, 2004. Disponível em http://172.25.14.55/teste_Estimativas_2004/UF_Municipio.zip (Acessado em 15/03/2010)

JANNUZZI, Paulo de Martino. Projeções populacionais para pequenas áreas: modelo e aplicações. Textos para Discussão. Escola Nacional de Ciências Estatísticas, Rio de Janeiro, v. 22, n. 1, p. 1-67, 2006.

MOREIRA, M. M. O Novo padrão demográfico e as consequências socioeconômicas da transição demográfica na Amazônia brasileira. Cadernos de Estudos Sociais (FUNDAJ),Recife, v. 12, n. 2, p. 285-314, 1996. In www.fundaj.gov.br (Acessado em 01/03/2010)

SZWARCWALD, C. L.; CASTILHO, E. A. Proposta de um Modelo para Desagregar Projeções Demográficas de Grandes Áreas em seus Componentes Geográficos. Revistade Saúde Pública / Journal of Public Health, SÃO PAULO, v. 23, n. 4, p. 269-276, 1989.Disponível em: www.scielo.br (Acessado em 03/03/2010) 